\title{
Stress echocardiography in coronary artery disease
}

\section{Ecocardiografia sob estresse em coronariopatia}

Joselina Luzia Menezes OLIVEIRA, Martha Azevedo BARRETO, Andréa Barbosa Ávila SILVA, Antônio Carlos Sobral SOUSA

\section{Abstract}

Doppler echocardiography is a simple, fast and noninvasive method to identify abnormal regional or global left ventricular function. One could consider this non-invasive method to be the best approach of all imaging techniques.

Stress echocardiography techniques are used for the diagnosis, risk stratification, prognosis and the study of myocardial viability in ischemic heart disease. There are many ways of subjecting the heart to stress for echocardiographic studies. For physically fit patients exercise stress testing using a treadmill or bicycle is employed and patients who are unable to exercise undergo pharmacological tests.

Although accurate diagnosis and a high prognostic value are achieved with both methods, there are new techniques under study, including the utilization of echocardiographic microbubble contrast for endocardial edge evaluation and for myocardial perfusion studies.

Descriptors: Stress. Echocardiography. Coronary disease.

\section{Resumo}

A ecodopplercardiografia é uma metodologia simples, rápida e não invasiva para identificar anormalidades regional e global da função do ventrículo esquerdo, podendo ser considerado o método não invasivo de maior aplicabilidade dentro das técnicas de imagem.

A ecocardiografia sob estresse é utilizada para diagnóstico, estratificação de risco, prognóstico e avaliação da viabilidade miocárdica na doença arterial coronariana. Várias são as formas de se submeter o coração ao estresse para o estudo ecocardiográfico. Para indivíduos com capacidade física preservada, utiliza-se o teste com esteira ou bicicleta e para aqueles sem condições de se exercitar, são usados os testes farmacológicos.

Apesar da boa acurácia diagnóstica e do valor prognóstico com os dois métodos já referidos, novas técnicas vêm sendo estudadas, como a utilização do contraste ecocardiográfico com microbolhas para avaliação das bordas do endocárdio e o estudo da perfusão miocárdica.

Descritores: Estresse. Ecocardiografia. Coronariopatia.

Echocardiography Laboratory of São Lucas Cardio-Ecolab Internal Medicine Department, Cardiology Section, Federal University of Sergipe

Correspondence address: Dra. Joselina Luzia Menezes Oliveira. Praça Graccho Cardoso, 76, Apto. 402 Bairro São José. Aracaju, SE, Brazil. CEP: $49015-180$

Tel: (79) 2116813. Fax: (79) 212-8854

E-mail: fmacedo@infonet.com.br saolucascardio@saolucas-se.com.br 


\section{INTRODUCTION}

Coronary arterial disease (CAD) constitutes the main cause of morbid-mortality in the modern world. In Brazil, according to the data of the Health Ministry, it is responsible for approximately one million hospitalizations and $25 \%$ of deaths that occur annually [1]. This makes early diagnosis and treatment critical. Over recent years the technological and therapeutic advances have brought a positive impact in reducing mortality and morbidity of the disease.

Echocardiography plays an important role in noninvasive diagnosis of ischemia and myocardial viability, risk stratification and prognosis of patients with CAD. It gives real time assessment with good spatial resolution of the myocardial segments of the left ventricle (LV), thus supplying information about the regional and global myocardial contractility both at rest and under stress [2,3].

Tests that submit the heart to stress aim at identifying the anatomico-functional targets of ischemia by reducing the contractile reserve of the segment of the LV wall, where stenosis of the coronary artery is fixed or dynamic [4].

Physiopathologic substrate - basis for the interpretation of echocardiography under myocardial ischemic stress

An imbalance between offer and demand of oxygen leads to myocardial alterations caused by ischemia, which follow a determined sequence of physiopathologic phenomena as was described by HEYNDRICKX et al. [5] in 1978, and denominated the ISCHEMIC CASCADE. This cascade includes the following events: perfusion heterogeneity, metabolic alterations, LV diastolic dysfunction, regional dyssynergia, electrocardiographic alterations and precordial pain. During systole in the normal myocardium, there is a thickening of the muscles that is easily seen by echocardiography. When submitting the heart to stress, whether by physical or pharmacological stimulation, the fourth stage of the ischemic cascade, which is a reduction or absence of systolic thickening, can be observed. This is an early event, which is sensitive and specific to ischemia.

The myocardial contractility is not uniform and increases from the subepicardium to the subendocardium, which is responsible for $67 \%$ thickening as demonstrated by echocardiography during systole [6]. Contractility of the meso and epicardial regions function as a "reserve" for situations that demand greater myocardial inotropism, such as physical or pharmacological stress. This is known as contractile reserve. For echocardiography to demonstrate ischemic alterations, a reduction of at least $50 \%$ of the resting coronary flow rate, with involvement of at least $20 \%$ of the parietal wall and around $5 \%$ of the myocardial mass are necessary.
The American Society of Echocardiography [7] recommends that the LV is assessed by standard echocardiographic planes, defining 16 segments and that the examinations should be recorded for future reviewing. Scores are allocated to each of the 16 segments, with one allocated to normal segments, two for segments with a reduced thickness (hypokinetic), three for segments without thickening (akinetic) and four for segments with diskinetic movements. The wall contractility score index (WCSI) is obtained by summing the confirmed scores of each of the segments, divided by the number of segments studied. The advantage of this analysis is to enable a study of all the VE segments and correlate them with the involved coronary artery (Figures 1 and 2).

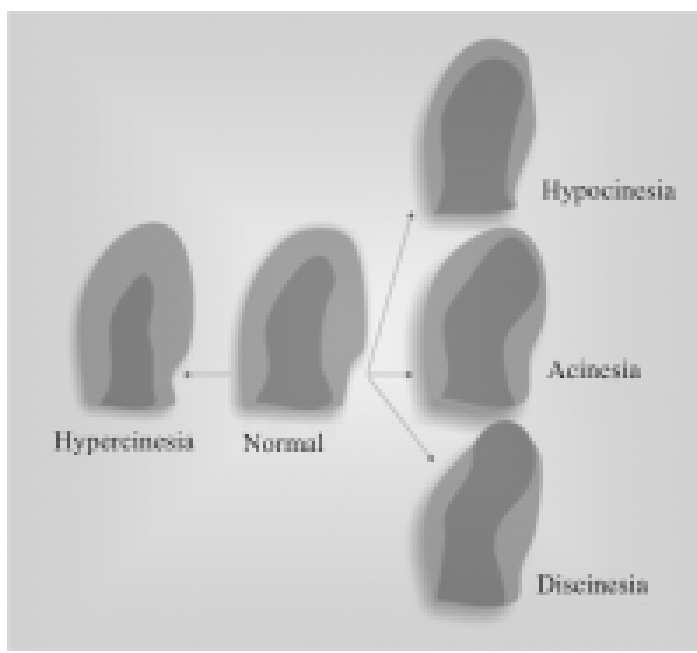

Fig. 1 - Myocardial response to stress

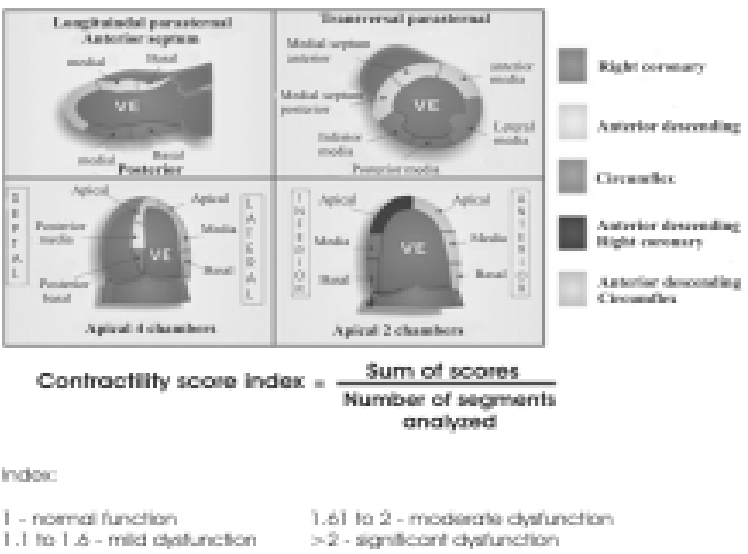

Fig. 2 - Segmental division of the left ventricle 


\section{Myocardial Viability}

In patients suffering from chronic coronary disease submitted to echocardiography, frequently akinetic and/or severely hypokinetic areas are observed. The distinction between (irreversible) scarred tissue or of a contractile dysfunction in a viable but not hypoperfused (hibernating myocardium) muscle, has relevant clinical implications, as it differentiates patients with viable myocardial areas who might benefit from coronary artery bypass grafting (CABG).

The duration of ischemia and the efficacy of postischemic perfusion are related to the recovery of the regional function in the affected area. When the ischemia is prolonged, cellular necrosis occurs with irreversible myocardial damage. On the other hand, when the period of ischemia is of a lesser duration and followed by reperfusion, the contractile dysfunction is recoverable, constituting a stunned myocardium [8]. However, when the reduction in the myocardial supply is chronic, it leads to a behavior called "SMART", as it suppresses contractile function, directing all the available energy to its functional integrity, enabling a future recovery of the coronary flow, a phenomenon denominated as hibernating myocardium.

This fact is owing to chronic stunning of the heart muscle with normal areas (islands), in regions with a reduction of coronary flow. In areas that suffer myocardial infarction, the presence of myocardial viability detected by echocardiography is due to the presence of contractile reserve [9]. When necrosis of the infarcted wall corresponds to more than $20 \%$ of the myocardial thickness (subendocardial layer), there is a loss of contractile function during resting, prejudicing the quantitative evaluation by the method [10].

In patients with a loss of greater than $20 \%$ of the myocardial thickness, the myocardial contractility at rest does not recover again. However, if there is echocardiographic or scintigraphic evidence of myocardial ischemia or hibernation in the infarcted area, the method will assist in the indication of myocardial revascularization to preserve the contractile reserve. It has been demonstrated that individuals submitted to myocardial revascularization can exhibit absence of parietal thickness in the infarcted area, however, the same can occur during exercise or any other form of stress. This fact explains the improvement in the functional capacity of infarcted patients who are submitted to revascularization, even without any improvement in the ventricular function at rest [11].

\section{Types of stress}

The most common forms of stress employed include physical exercise and pharmacological stress. Dobutamine is the most common drug used followed by dipiridamol and adenosine.
Stress echocardiography using pharmacological agents

Pharmacological tests contribute to the diagnosis of myocardial ischemia, and to direct therapeutic conduct in CAD carriers. Its utility is relevant in the stratification of risk of acute myocardial infarction (AMI), detection of myocardial viability, in the pre-operative tests for vascular surgery and the evaluation of transplantation patients.

Stress echocardiography evoked by dobutamine (SED)

Dobutamine, synthetic catecholamine, known for its great potential as an inotropic and a positive chronotropic agent (specifically when combined with atropine), leads to an increase in the myocardial demand for oxygen. Its adrenergic agonistic activity increases the heartbeat and myocardial contractility.

The standard protocol consists in a continuous infusion of dobutamine at an initial dose of $5 \mathrm{mcg} / \mathrm{kg} / \mathrm{min}$, with increments of $10,20,30$ and $40 \mathrm{mcg} / \mathrm{kg} / \mathrm{min}$, at three-minute intervals. At the dobutamine infusion peak, $0.25 \mathrm{mg}$ of atropine is administered at 1 -minute intervals $[12,13]$. New protocols for dobutamine-atropine include an earlier start of the atropine, with the dose of $20 \mathrm{mcg} / \mathrm{kg} / \mathrm{min}$ of dobutamine, in the case of patients not presenting with evident signs of myocardial ischemia and not having reached a minimum heartbeat of $100 \mathrm{bpm}$. An earlier utilization of atropine and its use of up to $2 \mathrm{mg}$ enables the termination of the protocol with lower doses of dobutamine and with less side effects, such as nausea and vomiting. Endovenous metaprolol is used as an antagonist of these effects if there are no contraindications.

During all the examination, the symptoms of the patient, the heart rate and rhythm are monitored by continuous electrocardiographic derivations. The arterial pressure and 12-lead electrocardiograms are registered at each stage of drug infusion and the regional and global functioning of the LV are analyzed by echocardiography.

Owing to the ischemia, stress echocardiography should be performed in a place where medical assistance is available in case of possible complications even for cardiopulmonary resuscitation if necessary.

The examination is positive for ischemia, always when there is an alteration in the regional contractility of the LV with the infusion of the dobutamine in a previously normal region, or an abrupt appearance of the "step" sign, that is, a reduction in the thickness of the LV wall. Also, cases in which there already are alterations in the segmental contractility and which worsen under stress, or cases in which alterations appear in another wall of the LV are considered positive. Thus, when there is a segmental alteration at rest, and an improvement occurs with low doses of dobutamine which again worsens with higher doses, the 
presence of ischemic viability is confirmed.

The general advantages of stress echocardiography using dobutamine include its great availability, low risk, absence of exposure to radiation, immediate results and lower costs than with myocardial scintigraphy. Additionally, extra information is provided for the differential diagnosis of precordial pain such as, for example, hypertrophic heart disease, aortic stenosis and prolapse of the mitral valve. Although SED is a fairly accurate examination for the diagnosis of $\mathrm{CAD}$, the addition of atropine increases its sensitivity, especially in patients treated with $\beta$-blockers.

SMART et al. [14] directly compared the accuracy of stress echocardiography with dobutamine and atropine (SEDA) and scintigraphy using computed tomography and an injection of with technetium-99m sestamibi (CMIBI), to detect CAD and its extension in a group of patients, and coronary angiography subgroups. The authors concluded that the results of the two examinations are very similar in detecting CAD with sensitivities of $87 \%$ for SED and $90 \%$ for CMIBI. The only difference was the greater specificity of SED $(91 \%$ versus $73 \%$ ). The two examinations gave similar results for the extension of the CAD. The sensitivity of the two tests was similar in all the angiographic subgroups of CAD with the involvement of multiple vessels. The severity of the injury, gravity and extension of ischemia was more frequently diagnosed in the left circumflex coronary artery $(\mathrm{Cx})$ using CMIBI. However, this method was less specific for CAD in multiple vessels, mainly owing to several perfusion defects.

SED in the stratification of post- acute myocardium infarction

The main determinants in the prognosis of post- AMI are related to the severity of the ventricular dysfunction, extension of the heart disease and the presence of residual ischemia. Echocardiography at rest and under stress enable intra-cavitary dimension evaluation, LV function, the presence of aneurysms, thrombi, papillary muscle dysfunction, interventricular connections post- AMI, rupture of the $\mathrm{LV}$ free wall, right ventricle infarction, presence of viability and ischemia with therapeutic and prognostic implications of great value for patients.

In cases of reduced ventricular function at rest, investigation of myocardial viability and the possibility of functional improvement after myocardial revascularization are of great importance in the evolution of heart disease. Low doses of dobutamine or dipiridamol are inductors that improve the contractility in viable myocardium. The accuracy of the two methods is similar in respect to predicting the functional recovery after AMI, but dobutamine has a greater sensitivity and dipiridamol a greater specificity [15].

In cases with normal ventricular function, the presence of myocardial viability is associated with a higher risk of re- infarction and unstable angina. In the EDIC study (Echo Dobutamine International Cooperative) [16] 800 survivors of AMI were studied soon after infarction proving that the presence of ischemia induced by SED is accompanied by a greater mortality. On the other hand, demonstration of the myocardial viability is the best predictor of recurring angina, although this does not influence survival.

A negative stress test, associated with normal or slightly reduced left ventricle function, is an excellent predictor of heart death, whilst induced ischemia effectively predicts the reoccurrence of angina and death.

\section{SED in the evaluation of myocardial viability}

When clinical indication to investigate the myocardial viability exists, echocardiography with drugs is totally recommended. A biphasic response, that is, an increase in myocardial contractility with low doses of dobutamine and a reduction in contractility at high doses, is considered the greatest indicator of myocardial recovery after revascularization. PIERARD et al. [17] evaluated the use of low doses of dobutamine in patients with AMI and compared the results with those of positron emission tomography. A rate of agreement in $79 \%$ of the viability evaluation cases was found between the two techniques. CWAJG et al. [18] reported that the final thickness of the myocardial wall at the end diastole is an important marker of myocardial viability in patients with suspicion of hibernation and that this is capable of accurately predicting functional recovery similar to using TL-201 scintigraphy. A measurement of the wall thickness at end diastole of less than $6 \mathrm{~mm}$ and an increase of the echo reflectivity is a not very sensitive, though specific for fibrosis, due to the extensive substitution of the meiocytes to fibrotic tissue.

In another important study, SMART et al. [19] reviewed the sensitivity and specificity of SED in patients with left ventricular hypertrophy. The authors observed that in patients with concentric reshaping, there was a excessively high number of false-negative examinations, even in the presence of significant coronary stenosis evidenced by angiography. On the other hand, the sensitivity was preserved in patients with normal wall thicknesses and in excentric hypertrophy carriers.

These authors also reported a utility of SED in the stratification of risk in patients with chronic ventricular dysfunction and left ventricle ejection fractions (FEVE) $\leq$ $30 \%$. In this study, 350 consecutive patients with moderate to severe LV dysfunction were submitted to SED, with persistent improvements occurring in $24 \%$ of the cases, just scarring in $28 \%$ and induced ischemia in $48 \%$. Patients with induced ischemia were revascularized and those with a persistent improvement or scarring received clinical treatment. Severe events, defined as revascularization, 
myocardial infarction or death, were rare in the group of patients with persistent improvement $(5 \%)$, infrequent in the patients with scarring (13\%), but significantly more common in the induced ischemia group (59\%). Severe cardiac events were rare $(8 \%)$ in patients with induced ischemia submitted to revascularization. Thus, SED can not only determine the etiology of LV dysfunction, but also identify the subgroup of patients who can benefit from myocardial revascularization.

Prognostic value of stress echocardiography evoked by dobutamine-atropine (SEDA) for cardiac events in patients who will be submitted to vascular surgery

Postoperative complications, such as death from cardiac causes and myocardial infarction, can be prevented with an adequate evaluation of cardiac risk. The presence of induced ischemia during SED was demonstrated as a predictor of postoperative cardiac events and became a widely used method for the evaluation of the cardiac risk in the vascular surgery preoperative procedures. Even with the reduction of associated mortality in complex vascular surgeries over the last years, the rate of cardiac events remains at 9 to $12 \%$ in the two-year postoperative period [20,21], with AMI being one of the principal causes of death in this population.

The initial study of POLDERMANS et al. [22], of 136 patients submitted to vascular surgery, demonstrated that the contractility alterations induced by SED were associated with a high risk of pre-operative events (heart death), nonfatal infarction and unstable angina. The positive predictive value of the test was $42 \%$ and the negative predictive value was $100 \%$. EAGLE et al. [23] demonstrated that patients who develop ischemia to SED with heart rates at less than $70 \%$ of the maximum value according to age, presented with a positive predictive value of $66 \%$ for cardiac events and $16.7 \%$ for mortality. When ischemia occurred with a greater heart beat, the patients presented with an intermediate risk for the occurrence of cardiac events (around 16\%). Patients with negative tests have a much smaller chance of events (around 1\%), and can be submitted to surgery without further investigations.

According to recommendations of the American College of Cardiology and the American Heart Association Task Force, SED has become a very useful method in the stratification of vascular surgery pre-operative risk, with a high negative predictive value. The examination should be performed in all patients with one or more of the following risk factors: over 70-years-old, diabetes mellitus requiring treatment, angina with Q waves on the electrocardiogram, history of arrhythmia or cardiac insufficiency.

\section{SED in transplanted patients}

The greatest long-term complication after heart transplantation and of great importance in the number of survivors, is the development of significant coronary artery disease. A diffuse, rapid and concentric involvement occurs affecting the epicardiac and transmural coronary arteries $[24,25]$. Early diagnosis of this artery disease in adults and children, using SED, has been demonstrated [26,27] by selecting patients for revascularization treatment, either by angioplasty or surgery, improving the overall survival rate after heart transplantation.

\section{Stress echocardiography evoked by physical exercise (SPE)}

SPE can be evoked by stationary bicycle or treadmill. In the majority of laboratories, the treadmill has been the choice, using classic standardized and validated protocols.

The initial studies were limited by the limited quality of the images obtained, however, with modern equipment incorporating digitalization of images, subsequent studies were performed, obtaining a mean sensitivity of $88 \%$ and mean specificity of $82 \%[28,29]$.

Studies comparing SPE and SED obtained a similar diagnostic accuracy, with the SED investigated by stress caused by dipiridamol [30], although endovenous drugs can cause side effects and provoke more prolonged ischemia than physical exercise [31]. FLEISCHMANN et al. [32] studied 2,637 patients, demonstrating a greater specificity with SPE (77\%) when compared to myocardial scintigraphy $(64 \%)$. Several works have established SPE in the risk and prognostic stratification of coronary disease [33]. ARRUDAOSLON et al. [34] studied the prognostic value of SPE in 5798 patients using a treadmill, and demonstrated that in normal examinations during the 5-year follow up period, the cardiac events (death or non-fatal AMI) were $5.3 \%$ for men and $3.1 \%$ for women.

Myocardial ischemia is characterized by the detection of new alterations of segmental contraction with physical effort or a worsening of pre-existent alterations, both reverted after the recovery period [35]. Fixed alterations of the segmental contraction are those present at rest and unaltered with effort (Table 1).

Attempting to demonstrate the value of SPE in aged patients, a study of 1,162 patients suspected of being CAD carriers in the period from December 2000 to July 2003 was presented in the I North-northwest Congress of Cardiogeriatrics and the XV North-northwest Congress of Cardiovascular Surgery in Aracajú (2003). Of these patients $285(24.5 \%)$ cases were over 65 -year-olds with ages ranging from 65 to 89 years (mean of 71.1 years), $109(38.2 \%)$ were male, $86(30.2 \%)$ were asymptomatic, $45(15.8 \%)$ had typical and 154 (54\%) atypical precordialgia. The following risk factors were evidenced: dyslipedemia $(76 \%)$, arterial hypertension $(66.3 \%)$, familial history of CAD $(56.8 \%)$ 
diabetes mellitus (19.6\%) and smoking (4.9\%). Of the patients studied, 25 (24.9\%) had been submitted to CABG, 21 (7.4\%) to angioplasty and $25(8.8 \%)$ had a history of AMI. Left branch blocks of the His' band were present in 32 (11.2\%) of the patients. During the procedure, only $23.9 \%$ (68 patients) did not attain the submaximum expected heart rate for the age, with $41.8 \%$ (119 patients) attaining maximum or greater heart rates. We obtained positive SPE for myocardial ischemia in $102(35.7 \%)$ patients, of which $86(84.3 \%)$ underwent coronary cineangiographies (Figure 3 ).

The results demonstrated normal examinations in 183 (64.2\%) cases, ischemia in $43(15.1 \%)$ patients, fixed ischemia in $38(13.3 \%)$ patients and mixed ischemia in $21(7.4 \%)$ patients. Compared with the coronary cineangiographies performed, SPE was concordant in the majority of cases (Table 2).

Thus we conclude that SPE is important, giving additional information to the clinical data, selecting with greater precision the aged patients in the indication for coronary cineangiographies. The efficacy of the method was also demonstrated in the subgroup of aged patients who presented with a heart frequency lower than the submaximum expected for the age. This methodology proved to be a viable low-cost reality, with accurate diagnostic evidence and without important complications in the studied age range.

The choice of the appropriate stress echocardiography modality involves selecting an adequate method of evoking stress. This must take into consideration the indication of

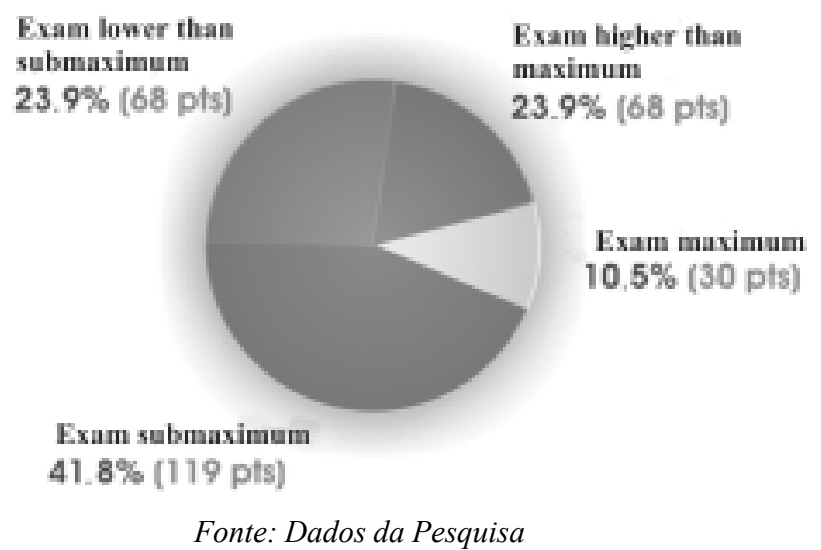

Fig. 3 - Heart rate behavior in aged patients during ESPE

the examination, the patient's conditions, the population to which the patient belongs, the medications being used, the examiner's experience and the conditions of the department in which the examination is being made, paying attention to the contraindications of each stress modality. The first choice for patients with physical capacity is physical exertion, with SED being the primary choice for the analysis of myocardial viability. In cases of severe arterial hypertension, significant arrhythmia, severe valve disease and hypertrophic myocardiopathy, dobutamine can not be used.

Table 1. Classification of the left ventricle response and clinical implications of stress echocardiography

\begin{tabular}{lllll}
\hline Response & Echocardiography at rest & Stress echocardiography & Interpretation & Clinical implication \\
\hline I - Normal & Normal & Hyperdynamic & CAD-/ischemia - & Normal, without CAD \\
II - ischemic & Normal & Abnormal & CAD + ischemia + & CAD/without prior AMI \\
III - fixed & Abnormal & without changes & CAD + ischemia - & prior single arterial AMI \\
IV - mixed & Abnormal & new changes & CAD $+/$ ischemia additional + prior multiple arterial AMI \\
\hline
\end{tabular}

Table 2. ESPE x Cinecoronariography

\begin{tabular}{llll}
\hline & Ischemic ESPE $(\mathrm{p}<0.000)$ & Fixed ischemic ESPE $(\mathrm{p}<0.000)$ & Mixed ischemic ESPE $(\mathrm{p}<0.000)$ \\
\hline Positive cinecoronariography & $27 \mathrm{pts}(62.7 \%)$ & $35 \mathrm{pts}(92.1 \%)$ & $18 \mathrm{pts}(85.7 \%)$ \\
Negative cinecoronariography & $4 \mathrm{pts}(9.3 \%)$ & $1 \mathrm{pts}(2.6 \%)$ & $1 \mathrm{pts}(4.7 \%)$ \\
Cinecoronariography not performed & $12 \mathrm{pts}(27.9 \%)$ & $2 \mathrm{pts}(5.2 \%)$ & $2 \mathrm{pts}(9.5 \%)$ \\
Total (102 patients) & $43 \mathrm{pts}(100 \%)$ & $38 \mathrm{pts}(100 \%)$ & $21 \mathrm{pts}(100 \%)$ \\
\hline
\end{tabular}

Source: research data 
Stress echocardiography with dipiridamol is prescribed for patients with DPOC and severe disturbance of conduction and the co-administration of atropine can not be made in cases of prostatic hypertrophy and glaucoma.

\section{Stress echocardiography in the evaluation for CABG}

Surgery and coronary angioplasty constitute effective therapeutic options in the treatment of duly selected coronary diseases. Recently, stress electrocardiography was associated with myocardial perfusion scintigraphy and radioisotopic ventriculography in the functional evaluation for the selection of patients and to measure the efficiency of these procedures. Apart from information about the location and the extension of ischemia, the technique helps to identify asymptomatic patients who may benefit in terms of survival of CABG procedures. For multiple arterial disease patients, stress echocardiography allows the integration of angiographic information in order to identify the vessels and lesions that caused the ischemia [36,37].

It is relevant that by using a single test, pharmacological stress echocardiography provides reliable information about the ventricular function and myocardial viability, which together with the presence of induced ischemia directs indication for CABG. The positivity of the posttreatment test indicates primary inefficacy, the presence of post-angiographic re-stenosis, occlusion of the aortocoronary shunts and/or progression of native circulation diseases [38].

\section{New uses for echocardiographic stress tests}

In patients suffering from hypertrophic cardiomyopathy exhibiting a LV outflow tract gradient at rest of less than 40 $\mathrm{mmHg}$, who present with advanced symptoms of angina and/or dyspnea [39], SED was performed before and after an application of ethanol. Only patients with induced gradients of more than $60 \mathrm{mmHg}$ were considered candidates for the procedure.

SED has been used as a valuable tool in the determination of contractile reserve in patients under cardiotoxic chemotherapeutic treatment [40].

SPE is indicated for the measurement of apparently moderate mitral stenosis at rest, but it shows great limitations with effort. This methodology assesses the pressure increase in the pulmonary artery [41]. In evaluations of cases of aortic stenosis with severe ventricular dysfunction [42], SED is indicated.

Recent data suggest that SPE may precisely identify patients susceptible to pulmonary edema at high altitudes [43] and asymptomatic carriers of the primary pulmonary hypertension gene who are at risk of developing pulmonary hypertension [44].

\section{Progress in echocardiographic stress tests}

New techniques such as tissue Doppler, the development in second harmonic imaging and the use of contrast agents have improved the diagnostic accuracy of the method [45].

Echocardiographic contrast agents are solutions containing microbubbles of air with perfluorocarbon gas, with diameters of 3 to 5 microns. They are injected in peripheral veins, opacity in the right cardiac chambers, pass through the pulmonary capillary barrier and fill the left cavities, improving the delimitation of the endocardial edges. The microbubbles fill the coronary arteries and the microcirculation, producing an increase in the ultrasonic reflection of the heart muscles, allowing a simultaneous evaluation of the myocardial perfusion and the segmental contractility, with the possibility of increasing the diagnostic accuracy of the method [46].

\section{CONCLUSIONS}

Stress echocardiography is a versatile instrument which derives the physiological information about the presence, location and extension of ischemia, by the response of regional thickening of the ventricular wall to stress, supplying diagnostic and prognostic data at varying stages of CAD.

The progressive refinement of imaging technology, with the use of contrast for a better definition of the endocardial edges and study of myocardial perfusion, allied to the accurate training of the observer, has increased the global feasibility of the methodology. With this, lives and resources have been saved in the management of coronary arterial disease.

\section{BIBLIOGRAPHIC REFERENCES}

1. DATASUS. Departamento de informática do SUS. Ministério da Saúde. Disponível em: http://www.datasus.gov.br/.

2. Marwick TH. Current status of non-invasive techniques for the diagnosis of myocardial ischemia. Acta Clin Belg 1992; 47:1-5.

3. Armstrong WF, Echocardiography in coronary artery disease. Progr Cardiovasc Dis 1988:30;267-88.

4. Gould KL, Lipscomb K. Effects of coronary stenoses on coronary flow reserve and resistance. Am J Cardiol 1974; 34:48-55.

5. Heyndrickx GR, Baig H, Nellens P, Leusen I, Fishbein MC, Vatner SF. Depression of regional blood flow and wall thickening after brief coronary occlusions. Am J Physiol 1978; 234:H653-9. 
6. Myers JH, Stirling MC, Choy M, Buda AJ, Gallagher KP. Direct measurement of inner and outer wall thickening dynamics with epicardial echocardiography. Circulation 1986; 74:164-72.

7. American Society of Echocardiography Committee on Standards, Subcommittee on Quantitation of Two-Dimensional Echocardiograms. Schiller NB, Shah PM, Crawford M, DeMaria A, Devereux R, Feigenbaum H et al. Recommendations for quantitation of the left ventricle by two-dimensional echocardiography. J Am Soc Echocardiogr 1989; 2:358-67.

8. Braunwald E, Kloner RA. The stunned myocardium: prolonged, post ischemic ventricular dysfunction. Circulation $1982 ; 66: 1146-9$

9. Rahimtoola SH. The hibernating myocardium. Am Heart J 1989; 117:211-21.

10. Vanoverschelde JL, Wijns W, Depre C, Essamri B, Heyndrickx GR, Borges $\mathrm{M}$ et al. Mechanisms of chronic regional post ischemic dysfunction in humans: new insights from the study of noninfarcted collateral-dependent myocardium. Circulation 1993; 87:1513-23.

11. Picano E, Sicari R, Landi P, Cortigiani L, Bigi R, Coletta C et al Prognostic value of myocardial viability in medically treated patients with global left ventricular dysfunction early after an acute uncomplicated myocardial infarction: a dobutamine stress echocardiographic study. Circulation 1998; 98:1078-84.

12. McNeill AJ, Fioretti PM, el-Said SM, Salustri A, Forster T, Roelandt JR. Enhanced sensitivity for detection of coronary artery disease by addition of atropine to dobutamine stress echocardiography. Am J Cardiol 1992; 70:41-6.

13. Pellikka PA, Roger VL, Oh JK, Miller FA, Seward JB, Tajik AJ et al. Stress echocardiography. Part II: Dobutamine stress echocardiography: techniques, implementation, clinical applications, and correlations. Mayo Clin Proc 1995, 70: $16-27$

14. Smart SC, Bhatia A, Hellman R, Stroiber T, Krasnow A, Collier BD et al. Dobutamine-atropine stress echocardiography and dipyridamole sestamibi scintigraphy for the detection of coronary artery disease: limitations and concordance. J Am Coll Cardiol 2000, 36: 1265-73.

15. Poli A, Previtali M, Lanzarini L, Fetiveau R, Diotallevi P, Ferrario $M$ et al. Comparison of dobutamine stress echocardiography with dipyridamole stress echocardiography for detection of viable myocardium after myocardial infarction treated with thrombolysis. Heart 1996; 75:240-6.

16. Sicari R, Picano E, Landi P, et al Prognostic value of dobutamine-atropine stress echocardiography early after acute myocardial infarction. Echo Dobutamine International Cooperative (EDIC) Study. J Am Coll Cardiol 1997;29:254-260.
17. Pierard LÀ, De Landsheere CM, Berthe C, Rigo P, Kulbertus HE. Identification of viable myocardium by echocardiography during dobutamine infusion in patients with myocardial infarction after thrombolytic therapy: comparison with positron emission tomography. J Am Coll Cardiol 1990; 15:1021-31.

18. Cwajg JM, Cwajg E, Nagueh SF, He ZX, Qureshi U, Olmos LI et al.End-diastolic wall thickness as a predictor of recovery of function in myocardial hibernation: relation to rest-redistribution T1-201 tomography and dobutamine stress echocardiography. J Am Coll Cardiol 2000, 35:1152-61.

19. Smart SC, Dionisopoulos PN, Knickelbine TA, Schuchard T, Sagar KB. Dobutamine-atropine stress echocardiography for risk stratification in patients with chronic left ventricular dysfunction. J Am Coll Cardiol 1999, 33:512-21.

20. Yeager RA, Moneta GL, Edwards JM, Taylor LM, McConnell DB, Porter JM. Late survival after perioperative myocardial infarction complicating vascular surgery. J Vasc Surg 1994; 20:598-606.

21. Mangano DT, Browner WS, Hollenberg M, Li J, Tateo IM. Long-term cardiac prognosis following noncardiac surgery. JAMA 1992; 268:233-9.

22. Poldermans D, Fioretti PM, Forster T, Thomson IR, Boersma E, el-Said EM et al. Dobutamine stress echocardiography for assessment of perioperative cardiac risk in patients undergoing major non vascular surgery. Circulation 1993; 87:1506-12.

23. Eagle KA, Brundage BH, Chaiman BR, Ewy GA, Fleisher LA, Hertzer NR et al. Guidelines for perioperative cardiovascular evaluation for noncardiac surgery. Report of the American College of Cardiology/American Heart Association/ Task Force on the assessment on practice guidelines. J Am Coll Cardiol 1996; 27:910-48.

24. Paavonen T, Mennander A, Lautenschlager I, Mattila S, Hayry P. Endothelialitis and accelerated arteriosclerosis in human heart transplant coronaries. J Heart Lung Transplant 1993; 12:117-22.

25. Schuler S, Matschke K, Loebe M, Hummel M, Fleck E, Hetzer $\mathrm{R}$. Coronary artery disease in patients with hearts from older donors: morphologic features and therapeutic implications. J Heart Lung Transplant 1993; 12:100-9.

26. Spes CH, Klauss V, Rieber J, Schnaack SD, Tammen AR, Uberfuhr $\mathrm{P}$ et al. Functional and morphological findings in heart transplant recipients with a normal coronary angiogram: an analysis by dobutamine stress echocardiography, intracoronary Doppler and intravascular ultrasound. J Heart Lung Transplant 1999, 18:391-8.

27. Pahl E, Crawford SE, Swenson JM, Duffy CE, Fricker FJ, Backer CL et al. Dobutamine stress echocardiography: experience in pediatric heart transplant recipients. J Heart Lung Transplant 1999, 18:725-32. 
28. Armstrong WF, O’Donnell J, Ryan T, Feigenbaum H. Effect of prior myocardial infarction and extent and location of coronary disease on accuracy of exercise echocardiography. J Am Coll Cardiol 1987; 10:531-8

29. Marangelli V, Iliceto S, Piccini G, DeMartino G, Sorgente L, Rizzon P. Detection of coronary artery disease by digital stress echocardiography: comparison of exercise, transesophageal atrial pacing and dipyridamole echocardiography. J Am Coll Cardiol 1994;24:117-24

30. Cohen JL, Ottenweller JE, George AK, Duvvuri S. Comparison of dobutamine and exercise echocardiography for detecting coronary artery disease. Am J Cardiol 1993; 72:1226-31.

31. Mathias Jr. W, Arruda A, Santos FC, Arruda AL, Mattos E, Osorio A et al. Safety of dobutamine-atropine stress echocardiography: a prospective experience of 4,033 consecutive studies. J Am Soc Echocardiogr 1999;12:785-91.

32. Fleischmann KE, Hunink MG, Kuntz KM, Douglas PS. Exercise echocardiography or exercise SPECT imaging? A meta-analysis of diagnostic test performance. JAMA 1998; 280:913-20.

33. Yao SS, Qureshi E, Sherrid MV, Claudhry FA. Practical applications in stress echocardiography: risk stratification and prognosis in patients with known or suspected ischemic heart disease. J Am Coll Cardiol 2003; 42:1084-90.

34. Arruda-Oslon AM, Juracan EM, Mahoney DW, McCully RB, Roger VL, Pellikka PA. Prognostic value of exercise echocardiography in 5.798 patients: is there a gender difference? J Am Coll Cardiol 2002; 39:625-31.

35. Oh JK, Seward JB, Tajik AJ. Stress echocardiography. In: Oh JK, Seward JB, Tajik AJ, eds. Echo manual. 2a. ed. New York: Lippincott-Raven Publishers Philadelphia; 1999. p.91-101.

36. Weiner DA, Ryan TJ, Parsons L, Fisher LD, Chaitman BR, Sheffield LT et al. Prevalence and prognostic significance of silent and symptomatic ischemia after coronary bypass surgery: a report from the Coronary Artery Surgery Study (CASS) randomized population. J Am Coll Cardiol 1991; 18: 343-8.

37. Beleslin BD, Ostojic M, Stepanovic J, Djordjevic-Dikic A, Stojkovic $\mathrm{S}$. Stress echocardiography in the detection of myocardial ischemia. Head to head comparison of exercise, dobutamine, and dipyridamole tests. Circulation 1994; 90:1168-78.
38. Varga A, PicanoE. Evaluation of immediate and long-term results of intervention by echocardiography: can restenosis be predicted? In: Nienaber CA, Sechtem U, eds. Imaging and intervention in cardiology. Kluwer: Dordrecgt; 1996. p. 387-99

39. Lakkis NM, Nagueh SF, Dunn JK, Killip D, Spencer WH. Nonsurgical septal reduction therapy for hypertrophic obstructive cardiomyopathy: one-year follow-up. J Am Coll Cardiol 2000; 36:852-5.

40. Dewolf D, Suys B, Verhaaren H, Matthys D, Taeymans Y. Low-dose dobutamine stress echocardiography in children and young adults. Am J Cardiol 1998, 81:895-901.

41. Tunick PA, Freedberg RS, Gargiulo A, Kronon I. Exercise doppler echocardiography as an aid to clinical decision making in mitral valve disease. J Am Soc Echocardiogr 1992; $5: 225-30$

42. Casale PN, Palacios IF, Abascal VM, Harrell L, Davidoff R, Weyman AE et al. Effects on dobutamine on Gorlin and continuity equation valve areas and valve resistance in valvular aortic stenosis. Am J Cardiol 1992; 70: 1175-9.

43. Grünig E, Mereles D, Hildebrandt W, Swenson ER, Kubler W, Kuecherer H. Stress Doppler echocardiography for identification of susceptibility to high altitude pulmonary edema. J Am Coll Cardiol 2000; 35:980-7.

44. Grünig E, Janssen B, Mereles D, Barth U, Borst MM, Vogt IR et al. Abnormal pulmonary artery pressure response in asymptomatic carriers of primary pulmonary hypertension gene. Circulation 2000; 102: 1145-50.

45. Kornbluth M, Liang DH, Paloma A, Schnittger I. Native tissue harmonic imaging improves endocardial border definition and visualization of cardiac structures. J Am Soc Echocardiogr 1998; 11:693-701.

46. Crouse LJ, Cheirif J, Hanly DE, Kisslo JA, Labovitz AJ, Raichlen JS et al. Opacification and border delineation improvement in patients with suboptimal endocardial border definition in routine echocardiography: results of the phase III Albunex multicenter trial. J Am Coll Cardiol 1993 , 22:1494-500. 